\title{
Can Humanoid Service Robots Perform Better Than Service Employees? A Comparison of Innovative Behavior Cues
}

\author{
Ruth Maria Stock \\ Technische Universität Darmstadt \\ rsh@stock-homburg.de
}

\author{
Moritz Merkle \\ Technische Universität Darmstadt \\ moritz.merkle@stock-homburg.de
}

\begin{abstract}
This research compares human-robot interaction with human-human interaction. More specifically, it compares potential customer responses to a humanoid service robot's (HSR's) behavioral cues during service encounters with those expressed by a human service employee. The behavioral cues tested in this study include innovative service behavior, defined as the extent to which a service representative creates new ideas and solutions for the customer. Based on role theory and the expectancy disconfirmation paradigm, we propose that customers generally respond positively toward an HSR's artificial innovative service behavior cues. The experimental laboratory study with 132 student participants and an HSR of the Pepper type, shows positive responses to an HSR's artificial innovative service behavior, but that those responses are weaker compared to human-human interactions within a similar setting. Furthermore, innovative service behavior cues exceed customer expectations and therefore, lead to customer satisfaction and delight with the HSR.
\end{abstract}

\section{Introduction}

The field of social robotics is still young, and although much research has focused on creating human-like interactions for service robots [1], little attention so far has been paid to users' responses to service robots. This is surprising, as service delivery by humanoid service robots (HSRs) that "exist primarily to interact with people" [2] has become increasingly important in recent years. HSRs assist human users in various settings, such as retailing, hospitality, education, and health care [1]. For example, Marriott recently started using HSRs to provide room service [3]. Nestlé has placed hundreds of HSRs on shop floors to sell Nescafé in Japan [4]. The Japanese travel agency HIS runs the Henn-na Hotel almost completely with robots, which function as receptionists, luggage carriers, and room service personnel [5]. As these examples illustrate, HSRs' tasks are manifold, ranging from carrying customers' items and transportation services to welcoming and checking in customers or answering routine questions. As HSRs become increasingly important during service encounters [6], "the market of service robots is forecasted to grow" [1].

A key question for the successful application of HSRs should be to determine which artificial behaviors customers would appreciate coming from a service robot, i.e., would lead to positive affective or behavioral customer responses. Without this knowledge, firms would apply HSRs during the service encounter without knowing what they are doing, i.e., which responses they create at the boundary to their customers. Recent studies in psychology have examined innovative behavior by human service employees (HSEs) [7] as "service workers who personally interact with customers" [8]. As HSEs are the primary representatives of a company, they shape customers' experiences through their behavior [9]. However, knowledge whether HSRs are also able to shape customers' experiences with their behaviors is scarce.

So far, many studies have investigated the effects of innovative service behavior at the service encounter. Firms are increasingly encouraging their service representatives' innovative service behavior [10] [11], as it is expected to inspire customers with creative ideas and to create superior experiences for customers. Additional benefits of these helpful services provide a further approach to leverage firm's offers [12].

As service representatives often "are the service" in service contexts, service innovations will only succeed by implemented innovative service behavior [13]. Innovative service representatives can adapt to changing customer needs [14] and uncover those needs. The resulting customer experiences lead to an increase in customer delight and loyalty [15] [16], creating strong relationships with customers. Therefore it is essential that service representatives exhibit innovation [17] [18]. 
However, it is not easy to foster HSEs innovative service behavior. Firms need to incorporate the correct leadership styles [19], provide sufficient job autonomy to HSEs [20] and adequate continuous job challenges [21] to increase HSEs innovative service behavior at the customer encounter. Nonetheless there are problems upholding a constant innovative service behavior by demotivated staff in highly standardized service processes due to a lack of challenges. Therefore firms are trying to stimulate HSEs through expensive human resources programs, creativity trainings, gainsharing programs or service awards [12].

In contrast to HSEs, the application of HSRs benefits from highly standardized service processes and avoids the motivation problem of HSEs in nonchallenging repetitive tasks. This advantage of HSRs in that context raises the question if HSRs might beat HSEs regarding innovative service behavior in standardized service processes in customer interaction.

Human-robot interaction (HRI) literature largely focused on general robot acceptance [22] in daily life applications [23] [24], more lifelike HRI [25] [26], and improving communications in HRIs through emotional communication [27] [28].

However, research including managerial implications on how to apply a robot in the service encounter to meet needs of service companies is scarce. This research is based on prior findings showing that humans can observe a robot's expressed behaviors [29] [30] [31]. Previous research has shown that people use visual gender cues as a basis for their judgments about social robots [32] and react on social robotic [33] behavior.

Although this research clearly indicates that humans can discern a robot's artificial behaviors, robotic research remains silent about user responses to artificial behaviors expressed by HSRs during a service encounter. However, this represents a crossdisciplinary process, integrating technical knowledge of behavioral expression with psychological knowledge of interaction dynamics.

This study focuses on customer responses to an HSR's expression of innovative service behaviors during a service encounter. An HSR's innovative service behavior refers to the extent to which the HSR generates new problem-solving ideas and transforms these into use during the service encounter [12]. Innovative service behavior during the service encounter is considered to be a particularly important variable in HRI for several reasons. First, due to constantly changing customer requirements and changes in the service offer, HSEs are required to continually adapt in an innovative manner to changing customer needs [16]. Second, by offering new ideas during the service encounter, HSRs can inspire customers, and enhance the standard service with creative elements [34]. Third, it has been argued and shown for human-human interactions (HHI) that firms' efforts to build strong bonds with customers might succeed only insofar as their HSEs exhibit innovative behavior [13] [17] [18]. This study is the first of its type to examine customer responses to a frontline social robot offering behavioral cues that indicate innovativeness during a service encounter. Furthermore, it compares customer responses within an HRI with those of a similar HHI.

Hypotheses are tested within an experimental laboratory study in a hotel setting. In a $2 \times 2$ between subject design experiment with 132 student participants in the role of a customer, this study examined whether and how an HSR's innovative behavioral cues in a service encounter setting affect the subjects' responses.

\section{Theoretical Background \& Hypotheses Development}

The theoretical basis for exploring how consumers assess and respond to artificial innovative behaviors, expressed by a social robot is role theory [35]. A role is "a cluster of social cues that guide and direct an individual's behavior in a given setting" [30]. Role theory posits that individuals can act according to a socially defined position (role congruence) or in contrast to this position (role conflict). In a service setting, a commitment to an effective role performance could incorporate that giving good service will matter. Thus, according to role theory, consumers are likely to also form certain expectations toward a social robot in its role as service representative of its company. These role expectations are relevant for a consumer's responses toward artificial behaviors, expressed by the social robot during the service encounter.

The expectancy disconfirmation paradigm describes the process of satisfaction development [36] [37]. The concept has recently been applied in information systems (IS) research to measure and examine web-consumer satisfaction [38]. The paradigm predicts that consumers form expectations to which they compare a current service performance. "A comparison of expectations and perceptions will result in either confirmation or disconfirmation" [39]. Confirmation occurs when the consumer's service expectations are exactly met by the actually perceived service. In contrast, disconfirmation arises from the discrepancy between a consumer's expectations and the perceptions of the delivered service; it can occur in two types [40]: the service is better than expected (positive disconfirmation) or the expectations exceed 
the service performance (negative disconfirmation). Expectations refer to the "anticipated performance" [40]. Satisfaction is the outcome of the comparison process and is defined as "a pleasurable level of consumption-related fulfillment" [41].

According to the expectancy disconfirmation paradigm, consumers are likely to compare their expectations toward a social robot's innovative behaviors with the actually perceived behavior by the social robot. The outcome of the comparison process is likely to affect the consumers' affective and behavioral responses.

This framework examines how a social robot's artificial innovative service behavior influences the acceptance of an HRI compared with an HHI. As indicators of HRI/HHI acceptance, we examine satisfaction and delight with the service representative (HSR/HSE). Satisfaction with the HSR is defined as a person's evaluation of her or his interaction with an HSR/HSE [42]. Delight with the HRI/HHI refers to the person's excitement and pleasure in response to treatment received from the HSR/HSE [43]. Furthermore, the role of consumer's expectations and their fulfillment by the HSR is examined. The conceptual framework of the study appears in Figure 1.

(A) Model Hypotheses $\mathrm{H} 1$ and $\mathrm{H} 2$

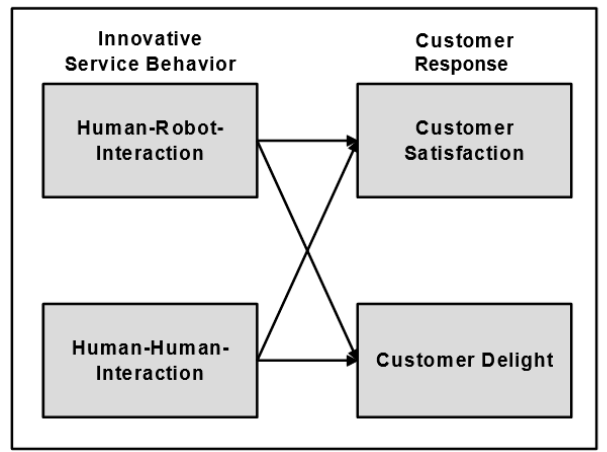

Figure 1. Framework of the Study

Innovative service behavior includes actions such as inventing new solutions for, introducing novel ideas to, and inspiring customers. In this sense, we argue that HSRs effectively shape human experiences through their relationships [11]. Innovative HSRs can thus make good beneficial connections with customers [16]. The resulting superior experiences have great potential to satisfy and delight customers and contribute to successful customer relationships [41]. By offering new ideas during the service encounter, HSRs can also inspire customers and enhance standard services with creative elements [28] [44]. Customers should then be satisfied and delighted [45]. Thus:

H1: An HSR's innovative service behavior positively affects customer acceptance of the HRI (i.e., satisfaction and delight with the HRI).

Whereas HSRs only impress their customers by behavioral cues that indicate innovative service behavior, innovative service behavior from human HSEs' contributes to building strong bonds with customers [17]. Furthermore, innovative HSEs can adapt to changing customer needs [16], uncover customers' latent needs, and make good connections with customers [16], all of which are less likely for HSRs. In other words, whereas customers rely on artificial behavioral cues during the HRI, they experience "true" behavioral cues from an HSE:

H2: The positive effect of an HSR's innovative service behavior on customer acceptance of the HRI (i.e., (a) satisfaction and (b) delight with the HRI) is weaker than for a similar HHI.

If HSRs want to provide a superior service, we argue that they may be expected to provide complete services to their customers - similar to HSEs - [46], but our qualitative study reveals that they rarely are required to propose ideas to refine existing services or introduce new services. Innovative service behavior by an HSR thus represents going "beyond the call of duty for customers" [47] or role requirements toward an HSR [48].

(B) Model Hypothesis $\mathrm{H} 3$

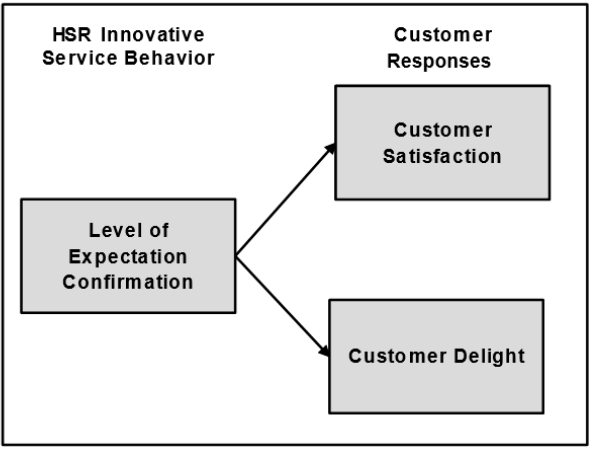
innovative service behaviors during the service encounter, they likely not only meet but even exceed customer expectations and deliver exceptional experiences to customers.

Such a positive disconfirmation of customer expectations leads to customer satisfaction and delight [45], particularly if the service experience seems surprising [16] [49]. Customers should be particularly surprised by innovative service behavioral cues, because they get something new from the service encounter that they previously did not expect. With their innovative service behavior, HSRs can exceed customers' expectations and likely delight their customers [50]. Thus, 
H3: Positive disconfirmation of customer expectations toward an HSR's innovative service behavior positively affects (a) customer satisfaction and (b) delight with the HSR.

\section{Data Collection and Sample}

\subsection{Mechanical basis and manipulation preparation}

The mechanical basis for the robot was the humanoid robot Pepper, a $120 \mathrm{~cm}$ high robot with 20 degrees of freedom, produced by Softbank. Robots of this type have previously been used in various HRI studies [51] [52].

Behaviors are typically communicated between humans by facial, vocal, and bodily expressions [53]. Pepper's platform only offers simple, moderate facial features. The LED head features a graphical face for the experiments. In line with recent evidence from psychology [54] [55], this study focuses on vocal and bodily expressions, which can be expressed easily by Pepper. Pepper's graphical programming tool Choregraphe [56] also supports the design of complex behaviors in an intuitive way.

The appropriate positions for the Pepper robot to express innovative service behaviors were identified in three steps. First, the authors relied on extant literature in psychology [57] [58] and innovation research that suggested various behavioral outputs [59] [60] [61]. Second, a qualitative study with $21 \mathrm{HSEs}$ and 30 potential customers (19-76 years of age, interview for $15 \mathrm{~min}$ on average in April/May 2016) was conducted to assess relevant verbal and bodily expressions for innovative service behavior during a service encounter. The qualitative interviews provided deeper insights to understand what types of behavior customers perceive as innovative. Third, the Pepper robot's bodily expressions were rated by 234 students (18-43 years of age; $67 \%$ men; $80 \%$ technical background). The respondents clearly identified those bodily and verbal expressions meant for expressing innovative service behavior. In addition, neutral behavior by the Pepper robot was also tested, and was clearly recognized by $93 \%$ of the students.

\subsection{Experimental setting}

Our experiment was carried out in a research lab associated with the authors' university. A room in the lab was outfitted to resemble a "hotel lobby", intended to welcome incoming guests to check in. The room was stocked with furnishings and objects likely to be familiar to test subjects and appropriate for a hotel lobby. Figure 2 depicts the experimental laboratory setting. A separate room, with no view of the experimental setting, was used for pre and post-session surveys with research subjects.

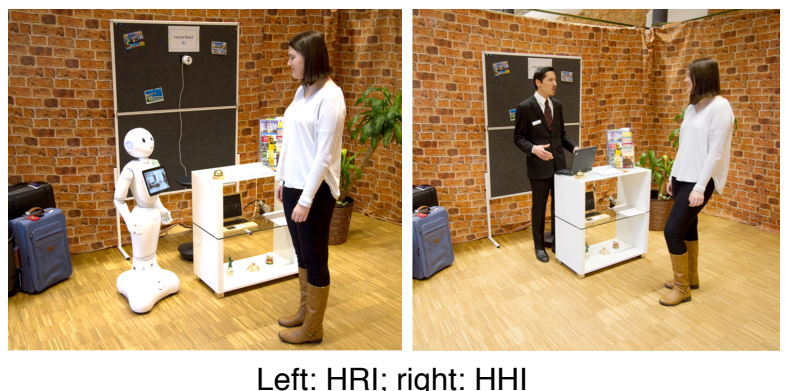

Figure 2. Experimental Setting of the Study

For all sessions, the experimental room was kept free of external sounds, and room lighting and room temperature were maintained at normal residential levels.

During the experiment, each participant in the role of a customer had to interact separately with the HSR or the confederate in the role of an HSE. All visual displays and sounds were recorded by external HD cameras, positioned in the room and on Pepper's body. The experimenter was not visible to the participants. At a hidden station, the experimenter was observing video streams from the cameras. We applied the Wizard of Oz method in which the participants were told that the HSR acted autonomously, whereas the robot was operated by the experimenter behind the curtain (Figure 3).

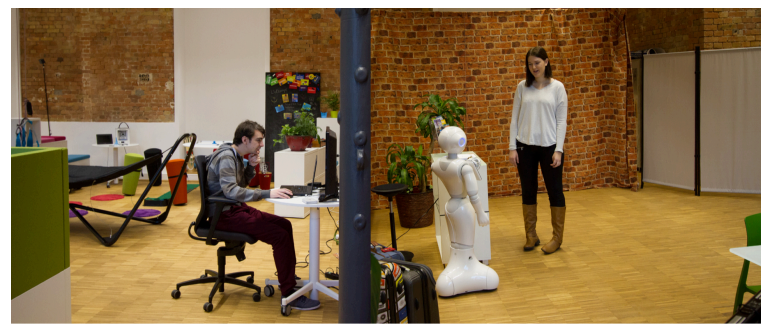

Left side: operator controlling the robot behind a curtain; right side: HRI

Figure 3. Experimental Setting of the Study

This method was first used by Gould et al. [62] in prototyping speech user interfaces, although the term Wizard of $\mathrm{Oz}$, (or originally the $\mathrm{Oz}$ paradigm,) was coined by Kelley [63]. The Wizard of Oz method has been widely used to design and collect language corpora in speech-based systems [64]. This method has also been employed in some projects involving HRI [65]. 


\subsection{Experimental design}

To avoid learning effects, we applied a between subject design [66]. When the subjects entered the room they were requested to check in the hotel that they had previously booked. This would be accomplished with the help of an HSR or an HSE. To further stimulate the interaction, the subjects had to ask for a room without carpet due to a dust allergy, and ensure that there was an electric kettle in the room. The manipulation contained four alternative sets of instructions, only one of which was given to each experimental subject.

Condition (1) contained an interaction with an HSR behaving in a neutral, but friendly and professional manner (HSR neutral); Condition (2) contained an interaction with an HSR behaving in an innovative manner. To invoke an innovative service behavior the service representative tried to come up with helpful solutions, easily linking facts together, thinking up new ways of doing something, coming up with bold plans and showing a vivid imagination. For instance by offering to reserve a table in the hotel restaurant if the customer mentioned to be hungry, by suggesting to shorten the check-in process for tired customers or customers in hurry, by proposing to switch the booked room to a closer one in case the customer decided to use the spa area and many other comparable behaviors. (HSR innovative); Condition (3) contained an interaction with an HSE (HSE neutral) and Condition (4) contained an interaction with an innovatively acting HSE (HSE innovative).

To ensure that each subject understood his or her assigned task, after reading the instructions they were asked to write down whether they understood their task. In the event of any issues, the experimenter corrected their understanding and asked them to again provide a written summary of their task, thereby double checking that our instructions were properly understood.

The effectiveness of the between-subject manipulation was checked by asking each subject after the experiment to assess the service representative's (HSR or HSE) innovative service behavior. Then, the mean scores of innovative service behaviors for all four experimental groups - HSR neutral, HSR innovative, HSE neutral, and HSE innovative - were calculated based on self-ratings by the participants. Table 1 shows that the desired effects from the manipulation of innovative service behavior [12] were achieved.

\subsection{Experimental subjects and confederates}

A total of 132 volunteer students enrolled in business, psychology, or engineering participated in this study. Calculation of the sample size with "G*Power 3.1.92" software suggested a minimum requirement of 25 per group to gather valid data [67] [68]. Thus, the realized sample size was considered as sufficient to test the hypotheses of this study. The sample comprised 59 females and 64 males with an average age of $\mathrm{M}=21.8(\mathrm{SD}=5.68)$.

As the focus of the study was on customer responses to HSEs' or HSRs' innovative service behavior, students were seen as customers. As an incentive, all participants received a payment of $\$ 10$ for completing the study. Additionally, they could enter into a lottery for three Amazon coupons worth $\$ 500, \$ 200$, and $\$ 100$ respectively.

To increase the level of immersion, intensively trained actors were used as confederates to play the roles of HSEs in the experiment. To reduce any confounding effects due to their personal communication style, and to standardize interaction with the company, standardized service scripts were used, similar to those commonly used for hotels in business practice. To increase the realism of the experiment, it was referred to an existing service offer by a hotel.

\subsection{Data collection and analysis methods}

Recalled that the primary purpose of this experiment was to identify and record data related to: (1) subjects' (in the role of a customer) perceptions and responses to an HSR's behavioral cues that indicated innovative service behavior, and (2) comparing this with the innovative service behavior-customer response relationship in an $\mathrm{HHI}$ between a confederate

Table 1. T-Test for Mean Differences between the Expectation and the Actual Experience

\begin{tabular}{|c|c|c|c|c|}
\hline $\begin{array}{l}\text { ISB-perception in the } \\
\text { setting with a ... }\end{array}$ & $\begin{array}{c}\text { Neutral Service } \\
\text { Behavior Setting (I) }\end{array}$ & $\begin{array}{l}\text { Innovative Service } \\
\text { Behavior Setting (J) }\end{array}$ & $\begin{array}{c}\text { Mean Difference } \\
\text { (I-J) }\end{array}$ & Sig. \\
\hline $\begin{array}{l}\text { Robotic Frontline } \\
\text { Employee }\end{array}$ & 5.328 & 6.349 & $-1.020^{*}$ & 0.000 \\
\hline $\begin{array}{l}\text { Human Frontline } \\
\text { Employee }\end{array}$ & 5.788 & 6.652 & $-.864 *$ & 0.000 \\
\hline
\end{tabular}


HSE and a customer. Data for participants in all four experimental conditions were collected both immediately prior to and immediately following subjects' 10-minute experiences in the hotel setting.

We relied on self-ratings by the subjects to assess customers' responses, i.e. customer satisfaction and customer delight as well as the perceived innovative behavior. To assess customer satisfaction, a three-item scale was adapted from Homburg and Stock [69]. The three-item scale for customer delight was inspired by Finn [49] and Riek et al. [70]. HSRs'/HSEs' innovative service behavior was assessed with a four-item scale used by Stock et al. [12]. All measures met the requirements of Cronbach's Alpha. In the prequestionnaire the subjects were asked for controls (age, technological affinity and their prior experience with robots) and the expected innovative service behavior.

\section{Results}

We computed t-tests and a multivariate analysis of variance (MANOVA) to check the effectiveness of our experimental manipulations, and to analyze the impact of HSR's and HSE's innovative service behavior on customer satisfaction and delight (Hypotheses 1 and 2). Significance level was set at $\alpha=0.05$.

Hypotheses $\mathrm{H} 1$ related to the influence of innovative service by an HSR on customer satisfaction and delight. Therefore, we tested two sets of dependent variables: customer satisfaction and customer delight. Against our expectations, the participants' mean scores for customer satisfaction were not significantly higher for participants with innovative service behaviors as compared to those interacting with a neutral HSR ( $p<$ $.05)$. Therefore, Hypothesis 1a was not supported. However, the results with respect to customer delight are highly significant. Thus, Hypothesis $1 \mathrm{~b}$ is supported.

Furthermore, Table 2 shows that the effects of an HSE's innovative service behavior on customer satisfaction and delight are higher than for an HSR.

Table 2. T-Test for Mean Differences of Satisfaction and Delight

\begin{tabular}{|c|c|c|c|c|c|}
\hline & $\begin{array}{c}\text { ISB } \\
\text { Outcome }\end{array}$ & $\begin{array}{c}\text { Neutral } \\
\text { Service } \\
\text { Behavior } \\
\text { Setting (I) }\end{array}$ & $\begin{array}{l}\text { Innovative } \\
\text { Service } \\
\text { Behavior } \\
\text { Setting }(\mathbf{J})\end{array}$ & $\begin{array}{l}\text { Mean } \\
\text { Difference } \\
(\text { I-J) }\end{array}$ & Sig. \\
\hline \multirow{2}{*}{$\begin{array}{l}\text { HSE } \\
\text { Inter- } \\
\text { action }\end{array}$} & $\begin{array}{c}\text { Customer } \\
\text { Satisfaction }^{1}\end{array}$ & 5.788 & 6.642 & $-.855^{*}$ & 0.000 \\
\hline & $\begin{array}{l}\text { Customer } \\
\text { Delight }^{I}\end{array}$ & 4.828 & 6.172 & $-1.343^{*}$ & 0.000 \\
\hline \multirow{2}{*}{$\begin{array}{l}\text { HSR } \\
\text { Inter- } \\
\text { action }\end{array}$} & $\begin{array}{c}\text { Customer } \\
\text { Satisfaction }^{I} \\
\end{array}$ & 6.085 & 6.321 & -.236 & 0.274 \\
\hline & $\begin{array}{l}\text { Customer } \\
\text { Delight }^{I}\end{array}$ & 4.960 & 5.717 & $-.758 *$ & 0.009 \\
\hline \multicolumn{6}{|c|}{$\begin{array}{l}\text { Notes: }{ }^{1} \text { Measured on a } 7 \text {-point Likert scale: } 1=\text { not at all, } 7=\text { extremely } \\
N(H S R \text { setting })=2 \times 33 ; N(H S E \text { setting })=2 \times 33 . \\
* p \leq .05 .\end{array}$} \\
\hline
\end{tabular}

Thus, Hypothesis 2 is supported, too.

Hypotheses H3 related to the effect of the expectation confirmation by the service representative's innovative service behavior on customer satisfaction and delight. First, we calculated a difference score between the participants' expectations toward an HSR's innovative service behavior ( $\mathrm{M}=$ $4.88, \mathrm{SD}=1.49$ ), assessed before the experiment and the perceived innovative service behavior of the HSR during the experiment $(\mathrm{M}=6.23, \mathrm{SD}=.82)$. As Table 3 shows, our innovative HSR clearly exceeded the participants' expectations (i.e., positive disconfirmation according to the confirmation disconfirmation paradigm $(\Delta \mathrm{M}=1.344 ; \mathrm{p}<.05)$. Furthermore, regression results in Tables 4 and 5 show that the positive disconfirmation in terms of an HSR's innovative service behavior contribute to both customer delight $(\mathrm{r}=.24, \mathrm{p}<.05)$ and customer satisfaction $(\mathrm{r}=.18, \mathrm{p}<.05)$ with the HSR. Therefore, Hypothesis 3 was supported.

Table 3. T-Test for Mean Differences between the Expectation and the Actual Experience

\begin{tabular}{|c|c|c|c|c|}
\hline & $\begin{array}{c}\text { Expectation } \\
\text { (I) }\end{array}$ & $\begin{array}{c}\text { Innovative } \\
\text { Experience }{ }^{1} \\
\text { (J) }\end{array}$ & $\begin{array}{c}\text { Mean } \\
\text { Difference } \\
\text { (I-J) }\end{array}$ & Sig. \\
\hline $\begin{array}{l}\text { Inter- } \\
\text { action with } \\
\text { HSR }\end{array}$ & 4.883 & 6.227 & $-1.344^{*}$ & 0.000 \\
\hline \multicolumn{5}{|c|}{$\begin{array}{l}\text { Notes: }{ }^{1} \text { Measured on a } 7 \text {-point Likert scale: } 1=\text { not at all, } 7= \\
\text { extremely } \\
N(\text { HSR setting })=2 \times 33 \\
* p \leq .05 .\end{array}$} \\
\hline
\end{tabular}

Table 4. Regression Results for the HSR's Positive Innovative Service Behavior Disconfirmation on Customer Delight

\begin{tabular}{|c|c|c|}
\hline & $\begin{array}{c}\text { Model } 1 \\
\text { (Control } \\
\text { Variables) }\end{array}$ & $\begin{array}{r}\text { Model } 2 \\
\text { (Direct } \\
\text { Effect) }\end{array}$ \\
\hline \multicolumn{3}{|l|}{ Control Variables } \\
\hline Age & .09 & .09 \\
\hline Technological Affinity & -.07 & -.06 \\
\hline Experience with Robots & .11 & $.13 *$ \\
\hline Service Quality & $.65^{*}$ & $.59 *$ \\
\hline \multicolumn{3}{|l|}{ Direct Effect } \\
\hline $\begin{array}{l}\text { Disconfirmation between } \\
\text { Expected and Experienced } \\
\text { ISB }\end{array}$ & - & $.24 *$ \\
\hline $\mathrm{R}^{2}$ (Adjusted $\mathrm{R}^{2}$ ) & $.44(.42)$ & $.49(.47)$ \\
\hline F-Value & $24.90 *$ & $24.51 *$ \\
\hline $\mathrm{F}_{\mathrm{I}}$ & $24.90^{*}$ & $13.36^{*}$ \\
\hline Incremental $\mathrm{R}^{2}$ & .44 & .05 \\
\hline
\end{tabular}


Table 5. Regression Results for the HSR's Positive Innovative Service Behavior Disconfirmation on Customer Satisfaction

\begin{tabular}{l|c|c|} 
& $\begin{array}{c}\text { Model 1 } \\
\text { (Control } \\
\text { Variables) }\end{array}$ & $\begin{array}{c}\text { Model 2 } \\
\text { (Direct } \\
\text { Effect) }\end{array}$ \\
\hline Control Variables & & \\
\hline Age & $.14^{* *}$ & $.13^{*}$ \\
\hline Technological Affinity & -.01 & -.00 \\
\hline Experience with Robots & .14 & .16 \\
\hline Service Quality & $.74^{* * *}$ & $.69^{* * *}$ \\
\hline Direct Effect & & \\
\hline $\begin{array}{l}\text { Disconfirmation between } \\
\text { Expected and Experienced } \\
\text { ISB }\end{array}$ & -- & $.18^{* *}$ \\
\hline $\mathrm{R}^{2}\left(\right.$ Adjusted R $\left.{ }^{2}\right)$ & & \\
\hline F-Value & $.58(.56)$ & $.61(.59)$ \\
\hline $\mathrm{F}_{\mathrm{I}}$ & $43.66^{* * *}$ & $39.18^{* * *}$ \\
\hline Incremental R & $43.66^{* * *}$ & $9.58^{* * *}$ \\
\hline Notes: See Table 4 & .58 & .03 \\
\hline
\end{tabular}

\section{Discussion}

\subsection{Implications for academic research}

The departure point of this study was the observation that companies increasingly apply HSRs at the boundary to their customers. We also know from extant innovation research that boundary spanners' innovative work behavior and, in particular, innovative services behavior is crucial to establish a fruitful customer relationship [41]. Therefore, it is surprising that IS research has not examined whether customers would expect HSRs at the boundary to their firm, and which behaviors of an HSR contribute to positive customer responses.

To our knowledge, this is the first of type study to examine the effects of artificial expressions of innovative service behavior by an HSR, compared with the effects from the HHI. Our study contributes to IS research and several important respects: First, our findings introduce a new phenomenon to IS research, HSR at the boundary between organizations and their customers. To our knowledge, robotic research so far has largely been focused on the programming of human-like emotions and behaviors but hardly examined human expectations or responses to HSR. Also, management and psychology research did not examine HRI although this increasingly present phenomenon in organizations demands deeper knowledge. Our study contributes to this gap of research by examining HRI in a laboratory setting, depicting a real life problem of the boundary between organizations and their customers.
Second, we apply and empirically assess underlying psychological mechanisms, known from the HHI to the HRI. Specifically, we rely on role theory and the expectancy disconfirmation paradigm to understand the underlying mechanisms of how HSRs' innovative services behavior transmits to customer satisfaction and delight with the HSR. Our results reveal that, although the innovative service behaviors of the HSR are artificial, customers reward those behavioral cues with higher delight. This indicates that the customers are positively surprised by this behavior.

Third, we attempted to more deeply understand the effects of a positive disconfirmation of customer expectations toward the innovative service behavior by the HSR. Our results show that a positive disconfirmation leads to both, customer satisfaction and customer delight, which is consistent with extant research on the confirmation disconfirmation paradigm.

\subsection{Managerial contributions}

Our study also contributes to managerial practice. So far, we observe that organizations increasingly apply HSR all over the world at the interface with their customers. Interestingly, they hardly know about the customer responses to these activities. First of all, our study indicates that HSRs are accepted to some extent by the customers. It is possible to stimulate customer satisfaction and even customer delight with innovative behavioral cues by an HSR.

Second, our study further contributes to managerial knowledge in that it provides valuable insights about desirable robotic behaviors at the boundary between companies and their customers. Specifically, our results show that customers appreciate innovative service behaviors. Thus, companies should consider these artificial behavioral cues when programming their HSRs.

\subsection{Limitations and areas for future research}

This study is the first step to theoretically understand and empirically examine the effects of HSRs' innovative service behavior on the positive customer responses, and particular, customer satisfaction and delight with the HSR. Furthermore, to our knowledge, this is the first study that examines HRI in a laboratory setting with a real life content. Therefore, we did have little orientation to set the experimental setting. Although we pretested the experimental setting carefully, experimental settings on HRI in organizations need to be further refined. 
Furthermore, this research was restricted to the outcomes of HSRs' innovative service behavior. Beyond satisfaction and delight future research should inspect the role of HSRs in actor engagement in the context of value co-creation [71]. The use of HSRs shifts the notion of interaction and engagement beyond HSEs and simple self-service technologies. Therefore the presented experimental setting is suitable to examine actor engagement with non-human actors. Thereby third-raters could observe the actor engagement during HRI. Future research could examine other behavioral cues or even compare those cues and their effects. Future research could also examine the acceptance of social robots within the organization, e.g., as robotic assistant in organizations, or its effects on organizational constructs like culture and leadership.

Finally, our study is restricted to an experimental setting. Future research could examine our or similar research questions in a natural setting after HSRs have been more largely diffused in organizations.

\section{Acknowledgements}

The authors would like to thank the Förderverein für marktorientierte Unternehmensführung for the grateful support.

\section{References}

[1] M.-J. Han, C.-H. Lin, and K.-T. Song, "Emotional Expression Generation Based on Mood Transition and Personality Model", IEEE Transactions on Cybernetics, vol. 43:4, 2013, pp. 1290-1303.

[2] R. Kirby, J. Forlizzi, and R. Simmons, "Affective Social Robot", Robotics and Autonomous Systems, vol. 58, 2010, p. 322 .

[3] S. Jeffrey, and T. DeSocio, "Meet Wally. The Room Service Robot of the Residence Inn Marriott at LAX", Fox11, 2016, [http://www.foxla.com/news/localnews/93131443-story].

[4] Nestlé "Nestlé to Use Humanoid Robot to Sell Nescafé in Japan", 2016, [http:/www.nestle.com/ media/news/nestlehumanoid-robot-nescafe-japan].

[5] M. Rajesh, "Inside Japan's First Robot-Staffed Hotel", Japan Holidays, 2015, [http://www.theguardian.com/ travel/2015/aug/14/japan-henn-na-hotel-staffed-by-robots].

[6] J. W. Park, W. H. Kim, and M. J. Chung, "Artificial Emotion Generation Based on Personality, Mood, and Emotion for Life-Like Facial Expressions of Robot", in P. Forbrig, F. Paternó, and A. Mark-Pejtersen (Eds.): HCIS 2010, IFIP AICT, vol. 332, 2010, pp. 223-233.
[7] J. P. J. De Jong, and R. Kemp, "Determinants of CoWorkers' Innovative Behaviour: An Investigation into Knowledge Intensive Services", International Journal of Innovation Management, vol. 7:2, 2003, pp. 189-212.

[8] N. J. Sirianni, I. Castro-Nelson, A. C. Morales, and G. J. Fitzsimons, "The Influence of Service Employee Characteristics on Customer Choice and Post-Choice", Advances in Consumer Research, vol. 36, 2009, p. 967.

[9] D. Grewal, M. Levy, and V. Kumar, "Customer Experience Management: An Organizing Framework", Journal of Retailing, vol. 85:1, 2009, pp. 1-14.

[10] N. Moosa, and P. Panurach, "Encouraging Frontline Employees to Rise to Innovation Challenge", Strategy and Leadership, vol. 36:4, 2008, pp. 4-9.

[11] S. Chang, Y. Gong, and C. Shum, "Promoting Innovation in Hospitality Companies through Human Resource Management Practices", International Journal of Hospitality Management, vol. 30:4, 2011, pp. 812-818.

[12] R. M. Stock, "Is Boreout a Threat to Frontline Employees' Innovative Work Behavior?", Journal of Product Innovation Management, vol. 32:4, 2016, pp. 574-592.

[13] Zeithaml, V. A., Bitner, M.-J., and Gremler, D. D., Services Marketing. McGraw-Hill, Irwin, Boston, 2009, p. 352.

[14] A. Rego, F. Sousa, C. Marques, and M. P. Cunha, "Hope and positive affect mediating the authentic leadership and creativity relationship", Journal of Business Research, vol. 67, 2014, pp. 200-210.

[15] F. J. Coelho, M. G. Augusto, and L. F. Lages, "Contextual Factors and the Creativity of Frontline Employees: The Mediating Effects of Role Stress and Intrinsic Motivation", Journal of Retailing, vol. 87:1, 2011, pp. 31-45.

[16] R. L. Oliver, R. T. Rust, and S. Varki, "Customer Delight: Foun- Dations, Findings, and Managerial Insight", Journal of Retailing, vol. 73:3, 1997, pp. 311-336.

[17] S. Cadwallader, C. B. Jarvis, M. J. Bitner, and A. L. Ostrom, "Frontline Employee Motivation to Participate in Service Innovation Implementation", Journal of the Academy of Marketing Science, vol. 38:2, 2010, pp. 219-229.

[18] A. Lievens, and R. K. Moenaert, "New Service Teams as Information-Processing Systems: Reducing Innovative Uncertainty", Journal of Service Research, vol. 3:1, 2000, pp. 46-65.

[19] B. Michaelis, R. Stegmaier, and K. Sonntag, "Affective Commitment to Change and Innovation Implementation Behavior: The Role of Charismatic Leadership and Employees' Trust in Top Management", Journal of Change Management, vol. 9:4, 2009, pp. 399-417. 
[20] N. Ramamoorthy, P. C. Flood, T. Slattery, and R Sardessai, "Determinants of Innovative Work Behaviour: Development and Test of an Integrated Model", Creativity and Innovation Management, vol. 14:2, 2005, pp. 142-150.

[21] O. Janssen, "Job Demands, Perceptions of EffortReward Fairness and Innovative Work Behavior", Journal of Occupational and Organizational Psychology, vol. 73:3, 2000, pp. 287-302.

[22] European Commission "Public Attitudes toward Robots", Special Eurobarometer 382, 2012.

[23] K. O. Arras, and D. Cerqui, "Do We Want to Share Our Lives and Bodies with Robots? A 2000 People Survey”, No. LSA-REPORT-2005-002, 2005.

[24] E. Broadbent, I. H. Kuo, Y. I. Lee, J. Rabindran, N. Kerse, R. Stafford, and B. A. MacDonald, "Attitudes and reactions to a healthcare robot", Telemedicine and e-Health, vol. 16:5, 2010, pp. 608-613.

[25] C. Breazeal, "Emotion and Sociable Humanoid Robots", International Journal of Human-Computer Studies, vol. 59:1, 2003, pp. 119-155.

[26] R. A. Brooks, "Robot: The future of flesh and machines", 2002.

[27] RoboticPerformanceCompany "Valerie the Robo Receptionist", 2004, [http://www.roboceptionist.com/].

[28] C. Bartneck, „Integrating the OCC Model of Emotions in Embodied Characters", Proceedings of the Workshop on Workshop on Virtual Conversational Characters: Applications, Methods, and Research Challenges, Melbourne, 2002.

[29] T. Zhang, B. Zhu, L. Lee, and D. Kaber, "Service Robot Anthropomorphism and Interface Design for Emotion in Human-Robot Interaction", 4th IEEE Conference on Automation Science and Engineering, 2008.

[30] T. Ogata, and S. Sugang, "Emotional Communication between Humans and the Autonomous Robot WAMOEBA-2 (Waseda Amoeba) which has the Emotion Model", JSME International Journal, vol. 43:3, 2000, pp. 568-574.

[31] A. Gaschler, K. Huth, M. Giuliani, I. Kessler, J. de Ruiter, and A. Knoll, "Modelling state of interaction from head poses for social human-robot interaction", Proc. of the Gaze in Human-Robot Interaction Workshop, 2012.

[32] F. Eyssel, and F. Hegel, “(S)he's got the Look: Gender Stereotyping of Social Robots", Journal of Applied Social Psychology, vol. 42:9, 2012, pp. 2213-2230.

[33] M. Giuliani, R. Petrick, M. E. Foster, A. Gaschler, A. Isard, M. Pateraki, and M. Sigalas, "Comparing task-based and socially intelligent behaviour in a robot bartender", Proceedings of the 15th ACM on International conference on multimodal interaction, 2013, pp. 263-270.

[34] V. J. Friedman, "The Individual as Agent of Organizational Learning", California Management Review, vol. 44:2, 2001, pp. 70-89.

[35] M. R. Solomon, C. Surprenant, J. A. Czepiel, and E. G. Gutman, "A Role Theory Perspective on Dyadic Interactions: The Service Encounter", Journal of Marketing, vol. 49, 1985, pp. 99-111.

[36] R. L. Oliver, and W. S. DeSarbo, "Response Determination in Satisfaction Judgements", Journal of Consumer Research. 10, 1988, pp. 250-255.

[37] Y. Yi, "A critical review of customer satisfaction", in V. A. Zeithaml (ed.) Review of Marketing, Chicago, American Marketing Association, 1990, pp. 68-123.

[38] V. McKinney, Y. Kanghyun and F. M. Zahedi, "The Measurement of Web-Customer Satisfaction: An Expectation and Disconfirmation Approach", Information Systems Research, vol. 13:3, 2002, pp. 296-315.

[39] J. Bloemer, and G. Odekerken-Schroeder, "Store Satisfaction and Store Loyalty: Explained by Customer- and Store-Related Factors", Journal of Consumer Satisfaction, Dissatisfaction, and Complaining Behavior, vol. 15, 2002, p. 70.

[40] Jr. Churchill, A. Gilbert, and C. Surprenant. "An Investigation into the Determinants of Customer Satisfaction", Journal of Marketing Research, vol. 19, 1982, pp. 491-504.

[41] R. L. Oliver, R. T. Rust, and S. Varki, "Customer Delight: Foun- Dations, Findings, and Managerial Insight", Journal of Retailing, vol. 73:3, 1997, p. 13.

[42] R. Stock, and M. Bednarek, "As They Sow, so Shall They Reap: Customers' Influence on Customer Satisfaction at the Customer Interface", Journal of the Academy of Marketing Science, vol. 42:4, 2014, pp. 400-414.

[43] D. C. Barnes, J. E. Collier, N. Ponder, and Z. Williams, "Investigating the Employee's Perspective of Customer Delight", Journal of Personal Selling \& Sales Management, vol. 33:1, 2013, pp. 91-104.

[44] M. C. Ottenbacher, and R. J. Harrington, "The Product Innovation Process of Quick-Service Restaurant Chains", International Journal of Contemporary Hospitality Management, vol. 19:6, 2009, pp. 523-541.

[45] R. T. Rust, and R. L. Oliver, "Should we Delight the Customer?", Journal of the Academy of Marketing Science, vol. 28:1, 2000, pp. 86-94.

[46] A. K. Jain, N. K. Malhotra, and C. Guan, "Positive and Negative Affectivity as Mediators of Volunteerism and Service-Oriented Citizenship Behavior and Customer Loyalty", Psychology \& Marketing, vol. 29:12, 2012. 
[47] J. C. Chebat, and P. Kollias, "The Impact of Empowerment on Customer Contact Employees' Roles in Service Organizations", Journal of Service Research, vol. $3: 1,2000$, p. 72 .

[48] V. T. Ho, and N. Gupta, "Testing an Empathy Model of Guest-Directed Citizenship and Counterproductive Behaviours in the Hospitality Industry: Findings from three Hotels", Journal of Occupational and Organizational Psychology, vol. 85:3, 2011, pp. 423-453.

[49] A. Finn, "Reassessing the Foundations of Customer Delight", Journal of Service Research, vol. 8:2, 2005, pp. 103-116.

[50] L. A. Bettencourt, and S. W. Brown, "Relationships among Workplace Fairness, Job Satisfaction, and Prosocial Service Behaviors", Journal of Retailing, vol. 73:1, 1997, pp. 39-61.

[51] E. Domingues, N. Lau, B. Pimentel, N. Shaffii, L. P. Reis, A. J. R. Neves, "Humanoid behaviors: From simulation to a real robot", Progress in Artificial Intelligence, Springer Berlin Heidelberg, 2011, pp. 352-364.

[52] A. Louloudi, A. Mosallam, N. Marturi, P. Janse, and V. Hernandez, "Integration of the Humanoid Robot Nao Inside a Smart Home: A Case Study", Proceedings of the Swedish AI Society Workshop (SAIS). Linköping Electronic Conference Proceedings, vol. 48, 2010, pp. 35-44.

[53] T. Bänzinger, D. Grandjean, and K. Scherer, "Emotion Recognition from Expressions in Face, Voice, and Body: The Multimodal Emotion Recognition Test (MERT)", Emotion, vol. 9:5, 2009, pp. 691-704.

[54] M. M. Bradley, and P. J. Lang, "Affective Reactions to Acoustic Stimuli", Psychophysiology, vol. 37, 2000.

[55] M. J. Magnee, J. J. Stekelenburg, C. Kemner, and B. de Gelder, "Similar Facial Electromyographic Responses to Faces, Voices, and Body Expressions", Neuroreport, vol. 18, 2007, pp. 369-372.

[56] E. Pot, J. Monceaux, R. Gelin, and B. Maisonnier, "Choregraphe: A Graphical Tool for Humanoid Robot Programming", in Robot and Human Interactive Communication (RO-MAN 2009), The 18th IEEE International Symposium, 2009, pp. 46-51.

[57] A. Pease, "Body Language: How to Read Others' Thoughts by their Gestures", Great Britain: University Printing House, Oxford, 1981.

[58] J. Fast, "Body language”, New York: Evans, 1970.

[59] S. Shamsuddin, H. Yussof, L. I. Ismail, S. Mohamed, F. A. Hanapiah, and N. I. Zahari, "Initial Response in HRI - A Case Study on Evaluation of Child with Autism Spectrum Disorders Interacting with a Humanoid Robot Nao", Procedia Engineering, vol. 41, 2012, pp. 1448-1455.
[60] S. Shamsuddin, H. Yussof, L. Ismail, F. A. Hanapiah, S. Mohamed, H. A. Piah, and N. I. Zahari, "Initial response of autistic children in human-robot interaction therapy with humanoid robot NAO”, IEEE 8th International Colloquium on CSPA, 2012, pp. 188-193.

[61] Cohen, I., Looije, R., \& Neerincx, M. A. (2011, March). Child's recognition of emotions in robot's face and body. In Proceedings of the 6th international conference on Human-robot interaction (pp. 123-124). ACM.

[62] J. D. Gould, J. Conti, and T. Hovanyecz, "Composing Letters with a Simulated Listening Typewriter", Communications of the ACM, vol. 26:4, 1983, pp. 295-308.

[63] J. F. Kelley, "An Iterative Design Methodology for User-Friendly Natural Language Office Information Applications", ACM Transactions on Office Information Systems, vol. 2:1, 1984, pp. 26-41.

[64] N. Dahlbäck, A. Jönsson, and L. Ahrenberg, "Wizard of $\mathrm{Oz}$ Studies - Why and How", Proceedings of the International Workshop on Intelligent User Interfaces, 1993.

[65] J. Xu, J. Broekens, K. Hindriks, and M. A. Neerincx, "Robot Mood is Contagious: Effects of Robot Body Language in the Imitation Game", Proceedings of the 2014 International Conference on Autonomous Agents and MultiAgent Systems, 2014, pp. 973-980.

[66] C. Atzmüller, and P. M. Steiner, "Experimental Vignette Studies in Survey Research", European Journal of Research Methods for the Behavioral and Social Sciences, vol. 6, 2010, pp. 128-138.

[67] F. Faul, E. Erdfelder, A.-G. Lang, and A. Buchner, "G*Power 3: A flexible statistical power analysis program for the social, behavioral, and biomedical sciences", Behavior Research Methods, vol. 39, 2007, pp.175-191.

[68] F. Faul, E. Erdfelder, A. Buchner, and A.-G. Lang, "Statistical power analyses using G*Power 3.1: Tests for correlation and regression analyses", Behavior Research Methods, vol. 41, 2009, pp. 1149-1160.

[69] C. Homburg, and R. M. Stock, "The Link between Salespeople's Job Satisfaction and Customer Satisfaction in a Business-to-Business Context: A Dyadic Analysis", Journal of the Academy of Marketing Science, vol. 32:2, 2004, pp. 144-158.

[70] L. D. Riek, P. C. Paul, P. Robinson, "When my Robot Smiles at Me: Enabling Human-Robot Rapport via RealTime Head Gesture Mimicry", Journal on Multimodal User Interfaces, vol. 3:1, 2010, pp. 99-108.

[71] K. Storbacka, R. J. Brodie, T. Böhmann, P. P. Maglio, and S. Nenonen, "Actor engagement as a microfoundation for value co-creation", Journal of Business Research, vol. 69:8, 2016, pp. 3008-3017. 